\title{
Lymphoblast to Leukocyte Ratio Measurement
}

National Cancer Institute

\section{Source}

National Cancer Institute. Lymphoblast to Leukocyte Ratio Measurement. NCI

Thesaurus. Code C105444.

The determination of the ratio of lymphoblasts compared to total leukocytes present in a sample. The measurement may be expressed as a ratio or percentage. 